\title{
A university conversation: using cloud technology to generate collaborative institutional policy for the enhancement of learning and teaching
}

\author{
Nick Almond \\ Liverpool Hope University, UK
}

\section{Abstract}

This paper discusses a cloud technology supported methodology for the creation of university policy through mass collaboration. The 'university conversation' methodology was deployed to facilitate the creation of a university learning, teaching and enhancement strategy that was ultimately authored by over 200 academic staff and had direct input from over 300 students. The methodology utilises the affordances (Gibson, 1986) of cloud technology to capture a large number of simultaneous conversations and to then mediate the iterative editing of the document through a sequence of synchronous and asynchronous collaborative events. The methodology demonstrates the potential of cloud technology to open communicative pathways between the 'significant networks' (Roxå and Mårtensson, 2009) where learning development often takes place and the institutional machinery that converts localised innovative practice into institutional policy.

Keywords: cloud technology; policy creation; mass collaboration; learning and teaching; quality assurance; university conversation.

\section{Introduction}

Creating meaningful and responsive change in institutional approaches to learning and teaching is a notoriously difficult and complex process (Fullan, 1999). A process made more complex by the robust and well-defined governance structures that are designed to support institutional Quality Assurance (QA). These structures are necessarily rigid and are often closed to many stakeholders within the university, particularly students (Dearlove, 2002). This leads to organisations where change is slow (Hannan and 
Freeman, 1984), localised (Roxå and Mårtensson, 2009) or inefficient (Roxå et al., 2011). University governance structures are consequently useful for audit-based quality assurance purposes but are far less suited to fostering innovation in learning development where more nuanced narratives of learning are needed (Hartley et al., 2011).

Generating effective institutional approaches to learning development occurs through a complex network of processes that are underpinned by the relationships between teaching staff, who support student learning at the classroom level, and the policy-making machinery that facilitates coordinated institutional change (Hartley et al., 2011). The development of co-ordinated institutional academic practices that support student learning are particularly difficult to establish in institutions where learning development is decentralised, as is the case at Liverpool Hope University. This work explores the potential for using cloud technology to open up communicative pathways between the university stakeholders that are directly engaged in student-facing learning development activities and the internal processes that create policy level institutional change, thus creating 'open institutional policy'.

\section{Theoretical framework}

\section{The reflective institution}

The auditing mechanisms, which are now interwoven into many institutional processes, are instrumental in what Biggs (2001) calls 'retrospective QA', which is fundamentally focused on accountability and conformity to external standards. These processes are essential for the modern university but they generally do not contain features that drive towards the improvement of quality. If institutions are to move towards improving current practice then they must move towards the pursuit of 'prospective QA', which is driven by processes that not only determine how fit-for-purpose current practices are, but demonstrate a clear coordinated drive towards transformation (Harvey and Askling, 2003). Here transformation is linked not only to the creation of transformative learning scenarios for the students, but it is present throughout the institution as a whole, where tangible changes in the institutional culture of learning and teaching are present.

Biggs' (2001) notion of the reflective institution, a spin on the popular concept of the reflective practitioner (Schön, 1983), is a useful framework for examining institutional approaches to learning development. Biggs unpacks the notion of Quality Assurance (QA) 
into a three-stage model of institutional reflective practice. The first stage, the Quality Model (QM), describes an institutionally defined 'espoused theory' of learning and teaching which acts as a driver for learning and teaching oriented decisions. The second stage, Quality Enhancement (QE), describes processes which review learning and teaching in light of this Quality Model and then facilitate the review and enhancement of practice through built-in mechanisms. Finally, Quality Feasibility (QF) describes institutional interventions which, as far as possible, remove all impediments to quality teaching. These interventions, which allow the reflective practice that occurs in classrooms to transition unimpeded into institutional learning and teaching discourse, fall into the third tier of Biggs' model, Quality Feasibility (QF). Discovering mechanisms that improve 'QF' is, as Biggs describes, 'the question that institutions rarely ask' (Biggs, 2001, p.223). This paper focuses on asking that question.

\section{Institutional learning and teaching policy creation}

Conventionally, university policy is generated through committee structures that are designed, through their targeted membership, to respond to the needs of the institution as they arise; for example, formulating amendments or creating new university policy as and when it is needed. This process occurs in a context where measures of institutional performance are becoming increasingly prominent. Performative measures such as the National Student Survey (NSS) and standardisation entities such as the Quality Assurance Agency (QAA) are dominant in university narratives both on a local and national scale (Ball, 2012). Consequently, the structural features of universities as organisations continue to drift towards the bureaucratic, requiring extensive tracking and regulation (Brown, 2004).

The result of increasing bureaucracy in any organisation is increasingly impoverished communities of people who can actuality elicit policy change at an institutional level, thus decreasing the reflexivity of the institution as a whole. This imposes stabilising forces on operational issues within the university at the expense of flexibility and situated control (Quinn and Rohrbaugh, 1983). With increasing control and structure, the institution drifts towards consolidation and continuity, ideal for Biggs' (2001) 'retrospective QA', but further away from the open system approach, which fosters adaptability and innovation. In order for the more enhancement focused 'prospective QA' to take place within in an institution, innovation must not only be encouraged but also incorporated into practice at an 
organisational level.

Achieving success in all three stages of Biggs' model is a difficult task, particularly in large institutions which are often fractured into a large number of small to medium sized departmental entities. In large fractured organisations practitioners enhance their practice in 'significant networks' (Roxå and Mårtensson, 2009). Roxå and Mårtensson (2009) highlight this phenomena using empirical evidence from their own institution. They describe hidden structures within faculties or departments, where critical discourse related to learning development occurs informally around departmental or even geographical loci. In these localised structures academic staff utilise high levels of situated control to engage in innovative practice and reflective dialogue. The innovation that occurs in these academic 'microcultures' is vital for the creation of discipline specific learning development, however this activity generally remains disconnected from the institution as a whole (Roxå and Mårtensson, 2011). Academic microcultures tend not to follow an institutional Quality Model (QM), since the formal university processes are largely 'invisible' (Roxå and Mårtensson, 2011, p.5) to them, but they do often remain committed to Quality Enhancement $(\mathrm{QE})$, albeit on a local scale. The fundamental issue with learning development that occurs within significant networks is that their innovative practice is not easily disseminated to the institution as a whole. There is a disconnect between these localised 'significant networks' and the institutional processes needed to create coordinated university wide change. This is largely due to failings in Quality Feasibility (QF) as the majority of stakeholders, with sufficient situated control to adapt, develop and implement quality enhancements, are not supported in the dissemination of their innovation.

It appears there is a need for more connective pathways between academic microcultures, or individual academics, and the formal structures of the institutions they exist within, in order to convert localised innovation into university policy. There are a few major barriers to this kind of conversion. Firstly, to gain a real cross-sectional insight into issues related to teaching as it happens in the classroom, a far greater membership to committees is required than what could be feasibly accommodated in any one meeting, which are conventionally dominated by the professoriate (Lapworth, 2004). Secondly, far greater connectivity to the student voice is required. Conventional student-staff liaison structures suffer from the same issues as committee meetings, as often only engaged students 
participate, whilst formalised meetings arguably stifle genuine critical discourse (Becher and Trowler, 2001). Finally, the policy chain itself is formal, slow and bureaucratic and is not conducive to the kind of reflective narratives which help real issues from the classroom to emerge (Wenger, 2006). Cloud technology can therefore be used as a platform to provide some of these pathways, linking cross-faculty spaces for reflective dialogue to a shortened and less bureaucratic university policy chain.

\section{Cloud technology and mass collaboration}

Cloud technology is a significant new emerging technological paradigm, which builds on the affordances of Web 2.0 technologies to shift computational processes away from the user whilst maintaining functional proximity. There remains some degree of ambiguity in these terms, principally due to significant overlap in where the terms are applied, however it is useful to delineate these terms by considering Web 2.0 as a trend in technology, particularly related to bidirectional communication, whereas cloud computing or cloud technology represents the technology itself (UNESCO, 2010).

Higher Education Institutions have for a long time used the lowest level of cloud computing, or 'Infrastructure as a Service' (laaS), by providing access to server space or remote access to institutional drives or file stores. More recently many institutions have progressed further up the cloud computing 'stack' to the 'Platform as a Service' (PaaS) model, utilising the Google App ecosystem or equivalent, to run their email and file storage. The highest level, as utilised in this project, is the Software as a Service (SaaS) model, where the software itself is executed on a platform and then accessed remotely using a web browser. This important abstraction away from running software at one's own personal computer creates a subtle but important leap in technological potential.

Cloud technology has a number of definable characteristics (Mell and Grance, 2011) however, the affordances which have most impact on the methodology outlined here are virtualisation and elasticity (Leymann, 2009). The process of virtualisation can be thought of as creating distance between the user and the physical manifestation of the technology, in this case, the computer that is running the software. The power and quantity of Google's server capabilities far outweigh those found in a conventional university, providing near limitless extension of resources. That is, the technology has elasticity; its resources grow 
or shrink on request and are not necessarily limited by the computational power of the machine the user has access to. Elasticity affords the opportunity to explore mass collaboration, such as synchronous collaborative writing, in ways that have previously not been possible.

This work uses the popular implementation of cloud technology GoogleDrive to virtualise the document creation process to facilitate mass-collaboration. This is achieved through simple technological extensions to existing and well-understood software, which ensures that the methodology requires very little user instruction upon deployment. From a user perspective, there appears to be very little difference between a virtual document and a traditionally editable document found in conventional desktop publishing software, such as Microsoft Word. The alignment of this technology with the very familiar affordances of desktop publishing software and conventional web technology generates short learning curves, high degrees of perceived usefulness and perceived ease of use and consequently very high levels of user acceptance (Davis, 1989). This remains one the of methodologies strongest features.

\section{A university conversation}

The 'university conversation' took place over two university-wide learning and teaching days. The learning and teaching days at Liverpool Hope University are distributed throughout the year and aim to act as a space for the dissemination of good practice and the sharing of innovative approaches to learning and teaching.

The goals of the university conversation, as decided by the university Learning and Teaching Committee (LTC), were as follows:

1. To engage all staff in reflective dialogue related to their learning development practice.

2. To capture the dialogue as best possible, to inform the creation of policy.

3. To consult with all university stakeholders, including students.

4. To create a university learning, teaching and enhancement strategy that will act as a Quality (QM) to guide reflection and enhancement of practice across the university.

5. To use the strategy to generate action plans that will support learning development. 


\section{Figure 1. The university conversation methodology.}

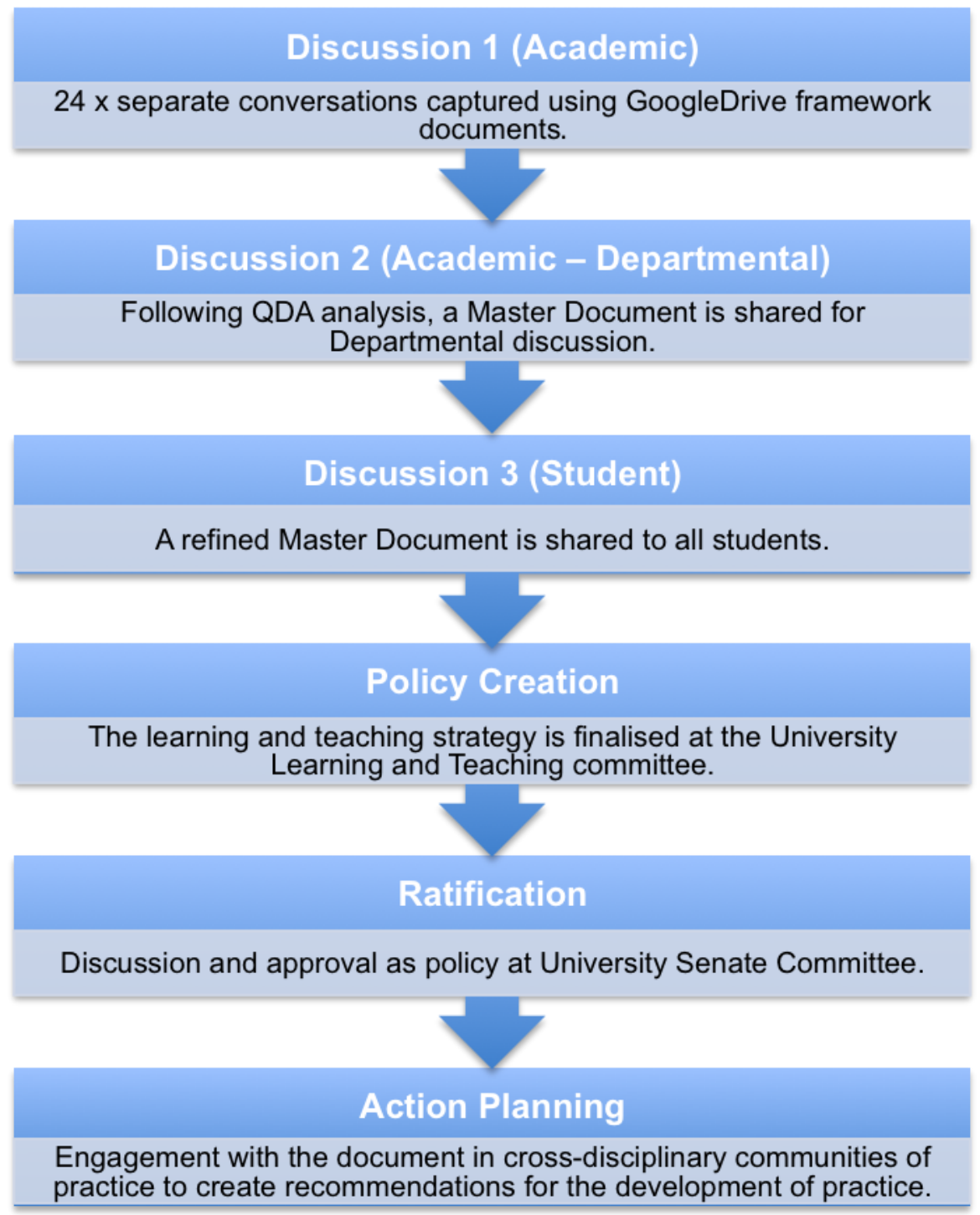

In order to meet the goals put forward by the institution for the university conversation, a network of documents hosted and shared using the GoogleDrive platform were utilised and a methodology was created (Figure 1) that was driven by sequential discussion and analysis of dialogue. Academics present on the day $(n=215)$ were split into groups of ten, to mirror the institution's tutorial model, and facilitators were guided to run the sessions as a community of practice (Wenger, 2006), where reflective dialogue and practice-focused narratives were encouraged and driven by a shared enterprise; in this case the development of a shared learning, teaching and enhancement strategy.

Building on other work that utilised GoogleDrive as a collaborative writing platform 
(Almond, 2014), the university conversation methodology was designed to use a combination of collaborative writing strategies, including 'group single author' and 'horizontal division writing', as outlined by Lowry et al. (2004). This new model for mass collaborative writing was designed to firstly capture the dialogue of the participants in each group within a single document (Figure 2) and then to stream these sub-documents into a meta-document for the purposes of group editing (Figure 3).

\section{Figure 2. A satellite group.}

Group single author - a collaborative writing strategy, Lowry et al. (2004).

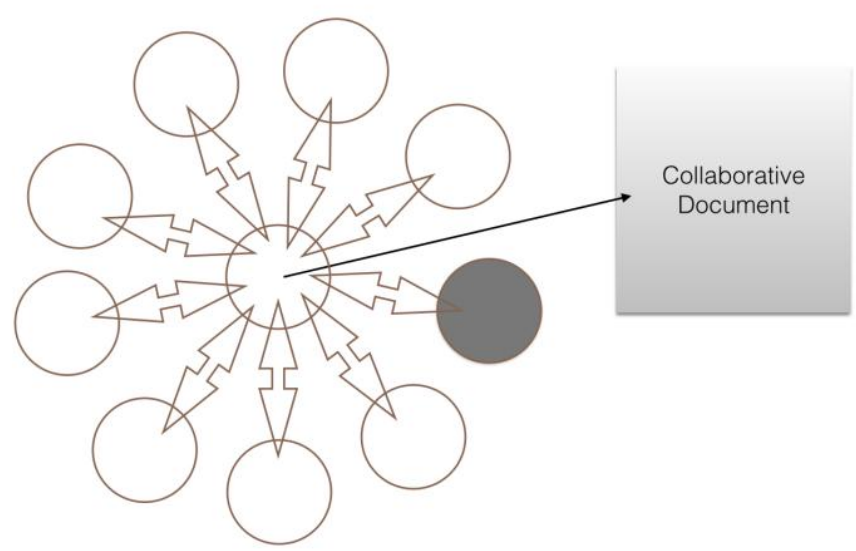

Solid circle represents the group facilitator

\section{Figure 3. Mass collaboration.}

An adapted form of horizontal division writing - a collaborative writing strategy, Lowry et al. (2004).

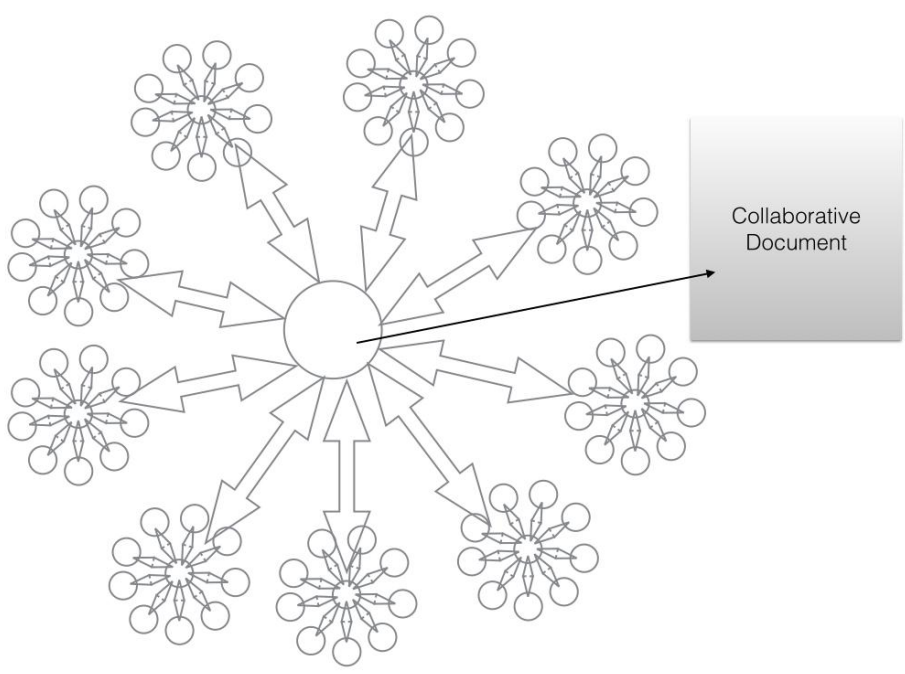


The result of this initial phase of the university conversation (Discussion 1) was over 20,000 words of raw 'conversation' between academics, generated from 24 separate groups (Figure 4). Using standard qualitative data analysis procedures (Thomas, 2006) a series of statements were generated from this dialogue and grouped into the themes (e.g. curriculum, assessment, technology). This more streamlined meta-document was opened up for consultation to academic staff in their respective departments (Discussion 2) where they used the commenting feature of GoogleDrive to engage directly with the statements related to learning and teaching practice (Figure 5). This consultation event was mirrored for the entire student body (Discussion 3 ) by sharing the document through the university email system. Following this final consultation phase, the document was converted to university policy at the university Learning and Teaching Committee (LTC). The final document centres on ten 'principles of learning, teaching and enhancement', which are each aligned with a series of 'underpinning expectations,' which as closely as possible reflect the dialogue that occurred in each of the early stages of the university conversation (see Figure 6 for an excerpt of the learning, teaching and enhancement strategy, the full strategy can be found at: http://tinyurl.com/LTHstrategy).

Figure 4. An example of the collaborative dialogue capture in each group. 


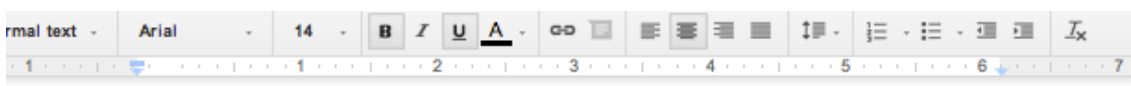

Learning and Teaching at Hope

Studying at Hope - What would you like your students to have as a learning experience? What is important?

What would you want your students to say about their experience?

How should we include the need to focus on employability?

What are the non-negotiables in terms of the learning experience?

What makes what you have included here specific to an experience at Liverpool

Hope?

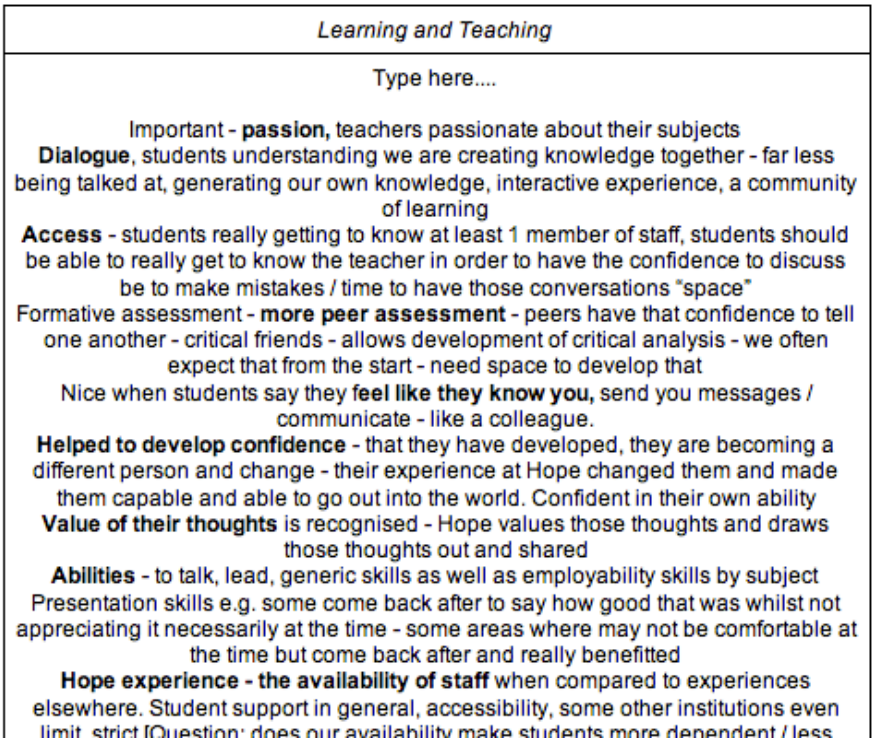

\section{Figure 5. An example of the threaded dialogue used to iteratively edit the}

\section{document.}

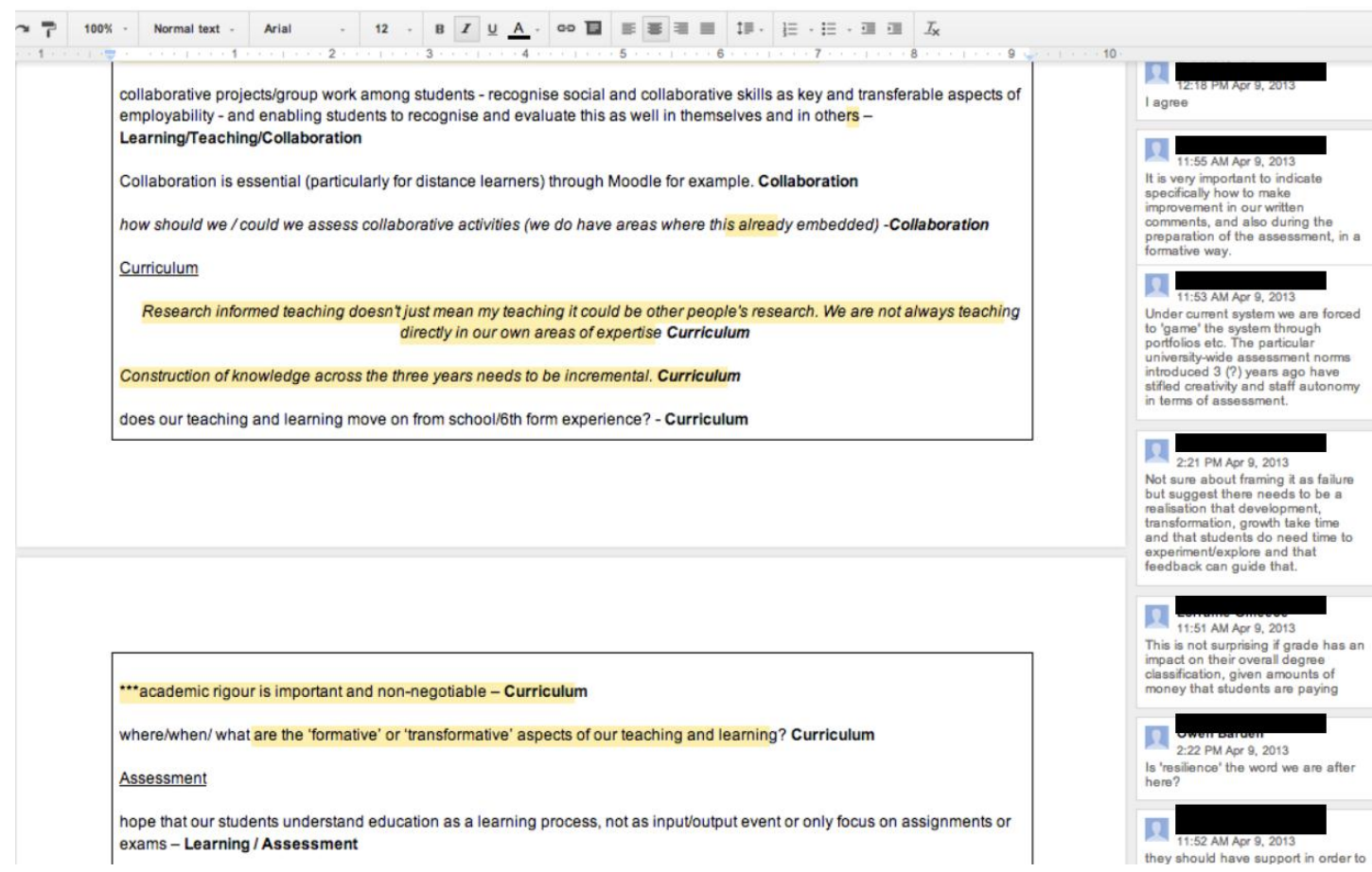


Figure 6. An excerpt from the final learning, teaching and enhancement strategy.

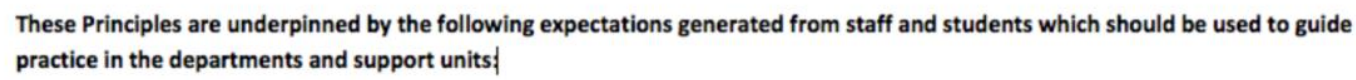
practice in the departments and support units:

\begin{tabular}{|c|c|c|}
\hline & Principle & Underpinning expectations \\
\hline \multirow[t]{8}{*}{1} & \multirow{8}{*}{$\begin{array}{l}\text { Learning in small groups } \\
\text { which allows the } \\
\text { development of } \\
\text { relationships with members } \\
\text { of staff }\end{array}$} & Students will be provided with the space to discuss and reflect on new knowledge in small groups of ten. \\
\hline & & $\begin{array}{l}\text { Tutors will recognise that students are in the early stages of their academic career and both parties will work } \\
\text { together to understand the distance between their own knowledge. }\end{array}$ \\
\hline & & $\begin{array}{l}\text { Student confidence will be nurtured through reassurance and encouragement, with the goal of creating high } \\
\text { quality scholars. }\end{array}$ \\
\hline & & Students should feel empowered by their learning experience. \\
\hline & & $\begin{array}{l}\text { Students will be encouraged to take ownership of their own learning and will aim to be confident autonomous } \\
\text { learners. }\end{array}$ \\
\hline & & $\begin{array}{l}\text { Students should feel connected to tutors and other students through their groups of ten and other } \\
\text { communities. }\end{array}$ \\
\hline & & $\begin{array}{l}\text { Tutors and students will endeavour to get to know and understand one another, using their relationship to } \\
\text { create a personalised learning experience. }\end{array}$ \\
\hline & & Students will be encouraged to develop resilience to academic challenge. \\
\hline \multirow[t]{5}{*}{2} & \multirow{5}{*}{$\begin{array}{l}\text { A coherent curriculum } \\
\text { supported by well-designed } \\
\text { assessments }\end{array}$} & Students will be introduced to new knowledge through a coherent and integrated curriculum. \\
\hline & & The curriculum will be high quality, adhering to national subject benchmarks as appropriate. \\
\hline & & Assessment should support and develop rather than merely measure student learning. \\
\hline & & Students will be introduced to, and encouraged to produce academically rigorous work. \\
\hline & & Tutors will be passionate about their subject and will encourage the same in their students. \\
\hline
\end{tabular}

\section{The university conversation and learning development}

In line with Hill and Tinker's (2013) thoughts on the need for integration of learning development activities at an institutional level, the university conversation was designed to move learning development activities away from individual student needs to a strategic institutional focus. Building on Surowiecki's (2005) notion of the 'wisdom of crowds' we have used cloud technology to harness the collective intelligence of an institution with the belief that the shared narratives of those who are directly engaged in student-facing learning development activities are critical to the development of effective institutional approaches to embedding learning development into curriculum and departmental practices.

The data arising from the methodology are vast and rich, with the potential to influence the strategic decisions of heads of departments, university committees and curriculum developers. These data represent the university more holistically than would normally be possible through conventional modes of governance and consultation. Although more advanced analytical techniques are required to fully realise the potential of this rich data set, even with rudimentary analytical techniques, it is possible to follow chains of dialogue, which expose the power of this kind of consultative activity. Two of these chains are presented in Table 1 and Table 2. 
Table 1. A dialogue chain through the university conversation related to the enjoyment and challenge of learning experiences.

\begin{tabular}{|c|c|}
\hline $\begin{array}{l}\text { Phase of the } \\
\text { methodology }\end{array}$ & Comments \\
\hline $\begin{array}{l}\text { Comments from the } \\
\text { university } \\
\text { conversation }\end{array}$ & $\begin{array}{l}\text { Learning should be fun and related to focused, } \\
\text { individual and collaborative learning activities. } \\
\text { Learning should be an enjoyable experience. }\end{array}$ \\
\hline $\begin{array}{l}\text { Comments from } \\
\text { asynchronous } \\
\text { discussion (academic } \\
\text { and student) }\end{array}$ & $\begin{array}{l}\text { I'm concerned about the idea that this (commenting } \\
\text { on enjoyable experience) is a primary driver in how } \\
\text { we teach. cf. threshold concepts and troublesome } \\
\text { knowledge and the productive role of discomfort. } \\
\text { (Academic A) } \\
\text { Academic F once used the phrase 'healthy } \\
\text { bewilderment' as a component of the research project } \\
\text { and we need to push students outside their comfort } \\
\text { zones. Learning needs to be meaningful more than } \\
\text { fun. (Academic B, replying to Academic A) } \\
\text { Yes. All this 'fun' and 'focused' stuff might often rather } \\
\text { miss the point that understanding and learning is often } \\
\text { a really hard struggle. I often want to teach people } \\
\text { things that are intellectually rewarding but not much } \\
\text { fun, I also like to tackle conceptual issues in a } \\
\text { deliberately unfocused way in order to encourage } \\
\text { students (and me) to really think for themselves. } \\
\text { (Academic C, replying to Academic B) } \\
\text { We need to develop our learning scenarios } \\
\text { recognising that these students are not (yet) } \\
\text { academics. It could be easy for us to pitch the }\end{array}$ \\
\hline
\end{tabular}




\begin{tabular}{|c|c|}
\hline & $\begin{array}{l}\text { conceptual content too high because we are over the } \\
\text { 'threshold' of understanding. (Academic D, replying to } \\
\text { Academic C) } \\
\text { Is 'resilience' the word we are after here? (Academic } \\
\text { E, replying to Academic D) } \\
\text { I'm just getting to the end of three years and will never } \\
\text { recover from the written tasks. I enjoyed the rest [of } \\
\text { the course] as an art student; creative work is what I } \\
\text { wished to do. I think the tutors assumed I was an } \\
\text { academic. (Student A) }\end{array}$ \\
\hline $\begin{array}{l}\text { Related expectations } \\
\text { in the learning, } \\
\text { teaching and } \\
\text { enhancement } \\
\text { strategy }\end{array}$ & $\begin{array}{l}\text { Students will be encouraged to develop resilience to } \\
\text { academic challenge. } \\
\text { Tutors will recognise that students are in the early } \\
\text { stages of their academic career and both parties will } \\
\text { work together to understand the distance between } \\
\text { their own knowledge. } \\
\text { Student confidence will be nurtured through } \\
\text { reassurance and encouragement, with the goal of } \\
\text { creating high quality scholars. }\end{array}$ \\
\hline $\begin{array}{l}\text { Learning } \\
\text { development } \\
\text { recommendations }\end{array}$ & $\begin{array}{l}\text { Students and staff should engage in dialogue at } \\
\text { waypoints through the year to evaluate student } \\
\text { expectations of the course and use these discussions } \\
\text { to reach a consensus on what can be successfully } \\
\text { achieved and to find the right level of academic } \\
\text { challenge. }\end{array}$ \\
\hline
\end{tabular}

Table 2. A dialogue chain through the university conversation related to feedback practice.

\begin{tabular}{|l|l|}
\hline $\begin{array}{l}\text { Phase of the } \\
\text { methodology }\end{array}$ & Comments \\
\hline Comments from the & Students should expect high quality feedback in a \\
\hline
\end{tabular}




\begin{tabular}{|c|c|}
\hline $\begin{array}{l}\text { university } \\
\text { conversation }\end{array}$ & timely fashion. \\
\hline $\begin{array}{l}\text { Comments from } \\
\text { asynchronous } \\
\text { discussion } \\
\text { (academic and } \\
\text { student) }\end{array}$ & $\begin{array}{l}\text { When I receive an essay back, I can't possibly improve } \\
\text { if the criticisms given to me look like they were written } \\
\text { by a three-year old with a biro. (Student B) } \\
\text { Use of the portal would be useful in this. Being able to } \\
\text { submit, and then review coursework (inc. tutor marks } \\
\text { and comments) online would be useful for backup and } \\
\text { seeing progress. (Student C) } \\
\text { An important thing here is how students can move from } \\
\text { one grade boundary into the next - e.g. if somebody } \\
\text { consistently gets } 67 / 68 \text { they need to be provided with } \\
\text { the information about how they can push into the } 70 \text { s. } \\
\text { (Student D) } \\
\text { Students need to be encouraged to understand WHAT } \\
\text { feedback is and when they are receiving it. This is } \\
\text { something we frequently score low on in NSS when I } \\
\text { know it is a particular strength. (Academic G) }\end{array}$ \\
\hline $\begin{array}{l}\text { Related } \\
\text { expectations in the } \\
\text { learning, teaching } \\
\text { and enhancement } \\
\text { strategy }\end{array}$ & $\begin{array}{l}\text { Students will be given clear, high-quality feedback in a } \\
\text { timely fashion. } \\
\text { Students will be encouraged to use and understand } \\
\text { their feedback through clearly established student and } \\
\text { tutor dialogue. }\end{array}$ \\
\hline $\begin{array}{l}\text { Learning } \\
\text { development } \\
\text { recommendations }\end{array}$ & $\begin{array}{l}\text { Ask students to evaluate their own feedback } \\
\text { opportunities, to encourage reflection and facilitate our } \\
\text { own development as practitioners. } \\
\text { Move towards electronic feedback. }\end{array}$ \\
\hline
\end{tabular}

The chains of dialogue represented in Table 1 and Table 2, exemplify the narratives that arise from this mode of consultation and how it was used to inform the creation of the 
policy document and subsequent action. In an asynchronous discussion, the academic staff use Meyer and Land's (2005) work on threshold concepts to challenge the nature of learning and whether it should be 'fun' or 'enjoyable'. The academic staff's values and ontological viewpoints related to the teaching of their subject demonstrate reflection on their teaching with references to other academic discourse (Academic $B$ ) and reflections on their approaches to building academic skills in the classroom (Academic $C$ ). The complexity of this narrative is expanded as Student $A$ (from the tangential student consultation event) provides their perspective, and describes how they will 'never recover' from their writing work, exposing the 'unsettling nature of higher level learning' (Cottrell, 2013, p.14). It is clear from this example that both the students and academic staff used this consultation event as a platform to reflect on their learning and teaching experiences, creating visible critical academic discourse related to learning that far transcends the localised and invisible discourse that happens in their significant networks (Roxå and Mårtensson, 2009).

In another example (Table 2), staff and students discuss the issue of feedback on assessments. In response to a statement referring to high-quality feedback, Student B candidly refers to the well known issues of legibility of tutor comments (Denton et al., 2008), but also surfaces his misconceptions of the nature of feedback by referring to the comments as 'criticisms'. The need for student and tutor dialogue relating to feedback is exemplified by students ( $C$ and $D$ ) and academic staff (Academic $G$ ) as they make useful developmental comments related to the use of university electronic resources and the need for clarity on closing the gap between current and goal attainment (Nicol and Macfarlane-Dick, 2006). These valuable insights and others like them, allow us to tap into the collective consciousness of the academic and student body to build the 'underpinning expectations' section of the strategy. It is within these statements that the collective voice of the academic and student body can be heard.

These example chains of dialogue (Table 1 and 2) highlight that all university stakeholders, including students, have the potential to contribute towards institutional narratives that can influence institutional approaches to learning development. By tapping into these narratives directly, it is possible to build a more nuanced, affective perspective of learning into university policy. Building on these narratives, the 'underpinning expectations' section of the strategy (Figure 6) makes frequent reference to the act of nurturing students and the role of dialogue in understanding where the students are 
situated in their academic development, along with the need to develop broader academic skills such as confidence and resilience to academic challenge. The inclusion of these more personalised and relationship-oriented expectations into university policy represents a strong move towards embedding learning development into the student experience. It also recognises at an institutional level the important role of intra-personal factors in supporting student learning development (Cottrell, 2013).

The early impact of this more nuanced policy can be seen from the first attempts at formulating practices using these expectations as a tool for reflection on current practice (Figure 1 - 'action planning' section). The proposed recommendations generated from the examples above, are underpinned by dialogue, reflection and mutual understanding. It is now the role of the departments to use these recommendations to stimulate learning development activity within their significant networks. It remains to be seen whether tangible institutional-wide change around learning development will arise from this activity. However, localised practice is beginning to emerge and there is now a shared platform for reflection on practice that can be used to mediate the conversation about learning development on a wider institutional scale.

\section{Conclusions}

This work describes a methodology for orchestrating a mass collaborative writing event, or 'university conversation', designed to channel multi-stakeholder dialogue into the conventionally closed university policy chain. From a technological perspective the methodology is not 'state-of-the-art', rather it aims to use the affordances of cloud technology to incrementally build on very traditional and widely used learning development technologies. This work is therefore in greater alignment with Neil Selwyn's notion of developing uses of technology as it is practically focused on what practitioners already use, that is 'state-of-the-actual' (Selwyn, 2010, p.69). Although subtle in its abstractions away from conventional non-technologically mediated collaborative activities, it uses the affordances of virtualisation and elasticity unique to cloud technology to mediate the kind of scaled collaboration that would otherwise be very difficult with offline tools.

This methodology opens channels into university governance structures by using technology to capture genuine learning development discourse in community of practice 
style contexts (Wenger, 2006). Using a multistage approach, dialogue was captured from the whole institution (Discussion 1); from departmental networks (Discussion 2); and from the students (Discussion 3); before being delivered directly to the top of the university policy chain (policy creation, ratification) and then used as a reflective tool to promote the development of practice (action planning).

Biggs' model of the reflective institution (Biggs, 2001) was used to guide the development of the methodology and through the construction of a 'learning, teaching and enhancement' strategy we have attempted to construct a collaborative institutional Quality Model (QM). We have created a space in which academic staff and students can contribute their voice towards current and desired learning development practice. By creating a common set of institutional goals to aim for we have created a substrate upon which quality enhancement (QE) can take place. Perhaps most importantly, by utilising the affordances of cloud technology, we have created pathways into policy creation mechanisms for a huge number of university stakeholders whose voices would not otherwise have been heard. The university conversation methodology shows great potential for reducing the barriers that prevent innovation in learning and teaching from becoming institutional policy and demonstrates the potential for modern communicative technologies to create new machinery for linking the collegial and audit driven components of the modern university.

\section{Reference List}

Almond, N. (2014, in press) 'Teaching in the cloud: a virtualised collaborative writing methodology for the development of postgraduate academic literacy', in Badenhorst.C. and Guerin, C. (eds.) Postgraduate writing pedagogies and research literacies in the 21st century. Leiden: BRILL.

Ball, S.J. (2012) 'Performativity, commodification and commitment: an I-spy guide to the neoliberal university', British Journal of Educational Studies, 60(1), pp. 17-28 [Online]. Available at:

http://www.tandfonline.com/doi/abs/10.1080/00071005.2011.650940 (Accessed: 18 September 2014).

Becher, T. and Trowler, P. (2001) Academic tribes and territories: intellectual enquiry and the culture of disciplines. Buckingham: SRHE and Open University Press. 
Biggs, J. (2001) 'The reflective institution: assuring and enhancing the quality of teaching and learning', The International Journal of Higher Education Research, 41(3), pp. 221-238 [Online]. Available at:

http://link.springer.com/article/10.1023/A:1004181331049 (Accessed: 15 September 2014).

Brown, R. (2004) Quality assurance in higher education: the UK experience since 1992. Psychology Press.

Cottrell, S. (2013) 'Revolution by stealth: the impact of learning development on democratising intelligence through constructive approaches to student support' Journal of Learning Development in Higher Education, Issue 6, November, pp. 1-21.

Davis, F.D. (1989) 'Perceived usefulness, perceived ease of use, and user acceptance of information technology', MIS Quarterly, 13(3), pp. 319-340 [Online]. Available at: http://www.jstor.org/stable/249008 (Accessed: 28 November 2014).

Dearlove, J. (2002) 'A continuing role for academics: the governance of UK universities in the post-Dearing era', Higher Education Quarterly, 56(3), pp. 257-275.

Denton, P., Madden, J., Roberts, M. and Rowe, P. (2008) 'Students' response to traditional and computer-assisted formative feedback: a comparative case study', British Journal of Educational Technology, 39(3), pp. 486-500 [Online]. Available at: http://doi.wiley.com/10.1111/j.1467-8535.2007.00745.x (Accessed: 17 April 2014).

Fullan, M. (1999) 'Change forces: the sequel', Journal of Educational Change, 1(2), pp. 205-209.

Gibson, J.J. (1986) The ecological approach to visual perception. London: Lawrence Erlbaum Associates.

Hannan, M. and Freeman, J. (1984) 'Structural inertia and organizational change', American Sociological Review, 49(2), pp. 149-164 [Online]. Available at: http://www.jstor.org/stable/2095567 (Accessed: 15 September 2014).

Hartley, P., Hilsdon, J., Keenan, C., Sinfield, S. and Verity, M. (eds.) (2011) Learning development in higher education (universities into the 21st century). Basingstoke: Palgrave Macmillan.

Harvey, L. and Askling, B. (2003) 'Quality in higher education', in Begg, R. (ed.) The dialogue between higher education research and practice. Netherlands: Springer Science pp. 69-83.

Hill, P. and Tinker, A. (2013) 'Integrating learning development into the student experience', Journal of Learning Development in Higher Education, Issue 5, March, pp. 1-12. 
Lapworth, S. (2004) 'Arresting decline in shared governance: towards a flexible model for academic participation', Higher Education Quarterly, 58(4), pp. 299-314.

Leymann, F. (2009) 'Cloud computing: the next revolution in IT', in Fritsch, D. (ed.)

Photogrammetric Week 2009. University of Stuttgart, Institute for Photogrammetry, Germany, pp. 3-12 [Online]. Available at: http://www.ifp.uni-

stuttgart.de/publications/phowo09/index.en.html (Accessed: 28 November 2014).

Lowry, P.B., Curtis, A. and Lowry, M.R. (2004) 'Building a taxonomy and nomenclature of collaborative writing to improve interdisciplinary research and practice', International Journal of Business Communication, 41(1), pp. 66-99 [Online]. Available at: http://job.sagepub.com/cgi/doi/10.1177/0021943603259363 (Accessed: 3 September 2014).

Mell, P. and Grance, T. (2011) The NIST definition of cloud computing: recommendations of the National Institute of Standards and Technology, National Institute of Standards and Technology, Special Publication 800-145, September. Available at: http://csrc.nist.gov/publications/nistpubs/800-145/SP800-145.pdf (Accessed: 28 November 2014).

Meyer, J.H.F. and Land, R. (2005) 'Threshold concepts and troublesome knowledge (2): epistemological considerations and a conceptual framework for teaching and learning' The International Journal of Higher Education Research, 49(3), pp. 373388.

Nicol, D.J. and Macfarlane-Dick, D. (2006) 'Formative assessment and self-regulated learning: a model and seven principles of good feedback practice', Studies in Higher Education, 31(2), pp. 199-218 [Online]. Available at: http://www.tandfonline.com/doi/abs/10.1080/03075070600572090 (Accessed: 9 January 2014).

Quinn, R.E. and Rohrbaugh, J. (1983) 'A spatial model of effectiveness criteria: towards a competing values approach to organizational analysis', Management Science, 29(3), pp. 363-377.

Roxå, T. and Mårtensson, K. (2009) 'Significant conversations and significant networks exploring the backstage of the teaching arena', Studies in Higher Education, 34(5), pp. 547-559 [Online]. Available at: http://www.tandfonline.com/doi/abs/10.1080/03075070802597200 (Accessed: 15 September 2014).

Roxå, T. and Mårtensson, K. (2011) Understanding strong academic microcultures - an exploratory study. Available at: 
http://www.ced.lu.se/documents/userfiles/pages/153_Microcultures_ever.pdf (Accessed: 18 September 2014).

Roxå, T., Mårtensson, K. and Alveteg, M. (2011) 'Understanding and influencing teaching and learning cultures at university: a network approach', Higher Education, 62(1), pp. 99-111.

Schön, D.A. (1983) The reflective practitioner: how professionals think in action. United States of America: Basic Books Inc.

Selwyn, N. (2010) 'Looking beyond learning: notes towards the critical study of educational technology', Journal of Computer Assisted Learning, 26(1), pp. 65-73 [Online]. Available at: http://doi.wiley.com/10.1111/j.1365-2729.2009.00338.x (Accessed: 11 January 2014).

Surowiecki, J. (2005) The Wisdom of Crowds. New York: Knopf Doubleday Publishing Group.

Thomas, D.R. (2006) 'A general inductive approach for analyzing qualitative evaluation data', American Journal of Evaluation, 27(2), pp. 237-246 [Online]. Available at: http://aje.sagepub.com/cgi/doi/10.1177/1098214005283748 (Accessed: 10 July 2014).

UNESCO (2010) Cloud Computing in Education, UNESCO Institute for Information

Technologies in Education, Policy Brief, September. Available at:

http://iite.unesco.org/files/policy_briefs/pdf/en/cloud_computing.pdf (Accessed: 1 June 2014).

Wenger, E. (2006) Communities of practice in and across 21st-century organizations.

Available at:

http://sitios.itesm.mx/va/dide2/enc innov/doctos/Article21 century organizations.pd f (Accessed: 30 November 2014).

\section{Author details}

Nick Almond is the Director of Masters courses and Chair of the Faculty Quality Learning and Teaching Committee in the Faculty of Education at Liverpool Hope University. His background is in physics but in recent years his research has focused on education, with a particular focus on learning and teaching and educational technology. He is a Fellow of the Higher Education Academy and is currently Director of the PGCert Learning and Teaching in Higher Education 
course, which is dedicated to the development of academic practice in early career academics at Liverpool Hope University. 